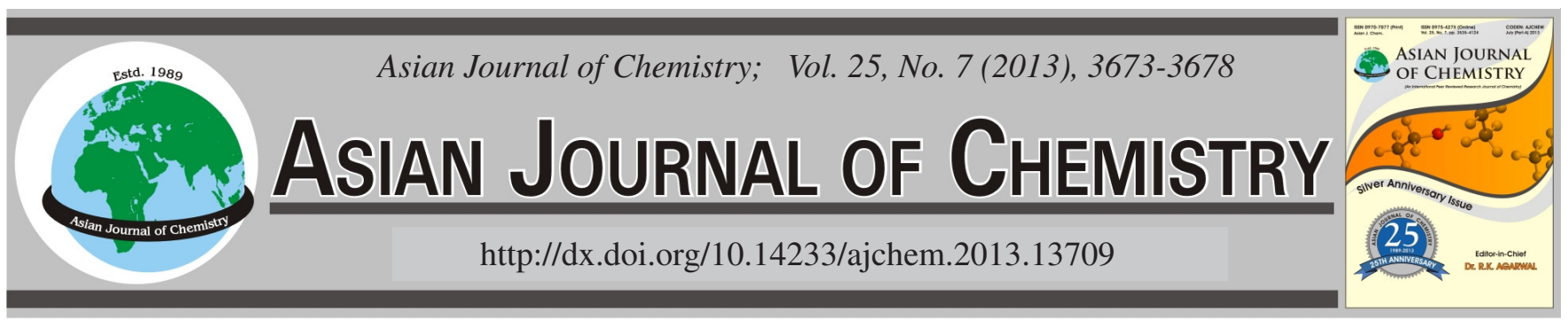

\title{
Comparison of Crystal Structure Between Carbonated Hydroxyapatite and Natural Bone Apatite with Theoretical Calculation
}

\author{
W.H. YANG ${ }^{1,2, *}$, X.F. XI ${ }^{1,2}$, J.F. $\mathrm{LI}^{1,2}$ and K.Y. CAI ${ }^{1,2}$ \\ ${ }^{1}$ College of Bioengineering, Chongqing University, Chongqing, P.R. China \\ ${ }^{2}$ Key Laboratory of Biorheological Science and Technology for Ministry of Education, Chongqing University, Chongqing, P.R. China \\ *Corresponding author: Fax: +86 23 65086425; Tel: +86 23 65086425; E-mail: yangweihu@cqu.edu.cn
}

\begin{abstract}
In this study, nanosized carbonated hydroxyapatite and stoichiometric hydroxyapatite were synthesized. Chemical analyses, as well as infrared spectroscopy and X-ray diffraction, were applied to investigate the composition, structure and chemical groups of all the samples. Furthermore, the structure and the crystal energy of all samples were analyzed by software and the mathematic methods. The results show that when $\mathrm{CO}_{3}{ }^{2-}$ is added into the solution after the reaction, the carbonated hydroxyapatite samples and natural bone apatite are similar in crystal structure, composition and crystallite size. Chemical analyses suggest that natural bone apatite and all synthetic carbonated hydroxyapatite samples have the same molecular formula. Meanwhile, the computed crystal energy indicates that the carbonated hydroxyapatite type-B substitution has lower crystal energy and better stability. Moreover, the fitting FTIR spectra prove that there is more type-B substitution than type-A substitution in all samples.
\end{abstract}

Key Words: Hydroxyapatite, Carbonate substitution, Structure simulation, Energy calculation.

\section{INTRODUCTION}

It is well known that the biological apatites are nonstoichiometric and poorly crystalline ${ }^{1,2}$. In our previous work ${ }^{3}$, we collected natural bone apatite from femur of a donor and compared its chemical composition and morphology with hydroxyapatite $\left[\mathrm{Ca}_{10}\left(\mathrm{PO}_{4}\right)_{6}(\mathrm{OH})_{2}, \mathrm{HA}\right]$. However, many foreign ions such as $\mathrm{CO}_{3}{ }^{2-}, \mathrm{F}^{-}, \mathrm{Na}^{+}$, etc., were found in the biological apatites. Among these ions, $\mathrm{CO}_{3}{ }^{2-}$ plays a vital role in bone metabolism due to its ionic composition as well as its functional properties favorable for bone growth ${ }^{4}$. Moreover, carbonate substitution decreases the degree of channel ion order, produces many vacancies, accordingly enhances the chemical activity and reduces the thermal stability. Thus, carbonate substituted hydroxyapatite (CHA) has better bioactivity and osteoconductivity. Generally, the weight percentage of carbonate content in the bone mineral is $\mathrm{ca}$. 4-8 wt $\%{ }^{5}$.

Many synthesis techniques have been used for preparation of carbonated hydroxyapatite, such as hydrothermal synthesis, homogenous precipitation, solid synthesis at high temperature and growth in the gel system ${ }^{6,7}$. Recently, Iafisco and Morales ${ }^{8}$ have synthesized carbonate-hydroxyapatite nanocrystals by using the sitting drop vapor diffusion technique. Moreover, Gibson and Bonfield ${ }^{9}$ have produced a single-phase, crystalline carbonate-substituted hydroxyapatite without sodium or ammonium ions by sintering calcium-rich carbonate-apatite in a carbon dioxide atmosphere. However, the crystallinity, configuration and component are influenced by different factors, such as temperature, pressure and reaction solvent, etc. Many experimental instruments such as X-ray diffraction (XRD), FTIR spectroscopy and C-H nuclear magnetic resonance (NMR) have been well-used in analysis of carbonated hydroxyapatite and bone apatite. With the application of computer modeling techniques in material science, the structure and the physical properties of hydroxyapatite and carbonated hydroxyapatite have been investigated by computer modeling. Peroos et al. ${ }^{10}$ have studied the uptake, structure and distribution of carbonate defects in hydroxyapatite with computer modeling. Yamamoto and Kawabata ${ }^{11}$ have analyzed the elastic properties of hydroxyapatite with the first-principles calculation. The structure of strontium substituted bioactive calcium phosphates has been surveyed by Murata and Matsunaga $^{12}$ with the first-principles principle. However, less research has been performed to investigate the structure and the component of carbonated hydroxyapatite with theoretical calculation.

Discussing the position of $\mathrm{CO}_{3}{ }^{2-}$ in hydroxyapatite structure, is beneficial to understand the biological and chemical properties of carbonated hydroxyapatite and biological apatite. Thus, the structure change and the substitutions of carbonated hydroxy- 
apatite have been investigated. In general, there are two substitution mechanisms: (1) the direct displacement of $\mathrm{OH}^{-}$by $\mathrm{CO}_{3}{ }^{2-}$ in hydroxyapatite structure called type-A substitution and (2) the replacement of $\mathrm{PO}_{4}{ }^{3-}$ tetrahedral groups by $\mathrm{CO}_{3}{ }^{2-}$ called type-B substitution. These investigations are based on the ideal model of carbonated hydroxyapatite. To our best of knowledge, the analysis of the structure and stability by structure simulation, or crystal energy, or the supersaturation degree of carbonated hydroxyapatite, has not been previously undertaken.

In this study, we investigated the influences of preparation methods on the crystallinity, component and structure of carbonated hydroxyapatite. Furthermore, the comparison on the structure between natural bone apatite and synthetic carbonated hydroxyapatite was carried out also. The crystal energy, crystallite size and supersaturation degree of different carbonated hydroxyapatite were calculated to estimate their stability. Carbonated hydroxyapatite was synthesized by homogenous precipitation method. $\mathrm{CO}_{3}{ }^{2-}$ ions were added into the reaction solution during or after the reaction. All samples were analyzed through X-ray diffraction pattern. Based on the chemical analyses, the molecular formulas of samples were presented and the supersaturation degrees were calculated accordingly. The composition and chemical groups were studied by infrared spectra. Furthermore, the FTIR spectra were fitted by Gaussians function. From the fitting spectra, the ratio of type-B to typeA substitution was estimated also.

\section{EXPERIMENTAL}

$\mathrm{Ca}\left(\mathrm{NO}_{3}\right)_{2}, \mathrm{Na}_{3} \mathrm{PO}_{4}, \mathrm{NH}_{4} \mathrm{OH}, \mathrm{Na}_{2} \mathrm{CO}_{3}$ of analytical reagent grade were purchased from Chengdu Kelong Chemistry Reagent Company (China).

General procedure: All the samples were prepared by coprecipitation method at $353 \mathrm{~K} .0 .5 \mathrm{~mol} \mathrm{Ca}\left(\mathrm{NO}_{3}\right)_{2}$ and 0.3 mol $\mathrm{Na}_{3} \mathrm{PO}_{4}$ were dissolved in $500 \mathrm{~mL}$ deionized water, respectively. Another solution was prepared by dissolving 0.3 mol of $\mathrm{Na}_{3} \mathrm{PO}_{4}$ in $500 \mathrm{~mL}$ deionized water and then adding 0.132 mol of $\mathrm{Na}_{2} \mathrm{CO}_{3}$ in it, stirring continuously until $\mathrm{Na}_{2} \mathrm{CO}_{3}$ was dissolved completely.

Sample 1: The $\mathrm{Na}_{3} \mathrm{PO}_{4}$ solution was added dropwise into the $\mathrm{Ca}\left(\mathrm{NO}_{3}\right)_{2}$ solution at a rate of $0.4 \mathrm{~mL} / \mathrm{min}$. The $\mathrm{pH}$ of the mixture was then adjusted to 10 by adding dilute ammonia solution.

Sample 2: The solution of $\mathrm{Na}_{3} \mathrm{PO}_{4} / \mathrm{Na}_{2} \mathrm{CO}_{3}$ was dropped into the $\mathrm{Ca}\left(\mathrm{NO}_{3}\right)_{2}$ solution with the same condition of sample 1 .

Sample 3: After the slurry of sample 1 was left for $4 \mathrm{~h}$, $\mathrm{Na}_{2} \mathrm{CO}_{3}$ was added into the slurry, stirring for $4 \mathrm{~h}$ at $353 \mathrm{~K}$. Then, the slurry was kept at $298 \mathrm{~K}$ for $48 \mathrm{~h}$.

All the precipitates were washed in deionized water for seven times to remove soluble impurities, then, dried at $373 \mathrm{~K}$ for $24 \mathrm{~h}$. Finally, all the samples were manually milled and the particles with a size of $<0.74 \mathrm{~mm}$ were separated by sieving.

The components of natural bones have been discussed in our previous study ${ }^{3}$. In this study, the XRD and IR data of human femoral bone from reference 3 were used for calculation.

Detection method: X-Ray diffraction analysis was carried out by a Philips X'Pert MPD powder diffractometer. $\mathrm{CoK}_{\alpha}$ radiation $(\lambda \mathrm{a}=1.78897)$ was used. The $2 \theta$ range was from $25-80^{\circ}$ and the data were collected with an acquisition time of
$5.0 \mathrm{~s}$ at a $0.03^{\circ}$ step size. The crystallite size was estimated from the X-ray diffractograms using the Scherrer formula ${ }^{13}$,

$$
\mathrm{D}=\frac{\mathrm{k} \lambda}{\beta_{1 / 2} \cos \theta}
$$

where $\mathrm{D}$ is the crystallite size $(\AA)$ estimated using the reflection (002 plane), $\mathrm{k}$ is a shape factor equal to $0.9, \lambda$ is the $\mathrm{X}$-ray wavelength $(1.78897 \AA), \theta$ is the diffraction angle related to the reflection (002) $(\theta=12.92)$ and $\beta_{1 / 2}$, expressed in radians, is defined as

$$
\beta_{1 / 2}=\left(B^{2}-b^{2}\right)^{1 / 2}
$$

where $\mathrm{B}$ is the diffraction peak width at half height and $\mathrm{b}$ is the natural width of the instrument.

To evaluate the functional groups, all samples crushed with $\mathrm{KBr}$ (IR grade) were scanned using Nicolet-170SX FTIR spectroscopy in the wavelength range of $4000-400 \mathrm{~cm}^{-1}$ at a resolution of $4 \mathrm{~cm}^{-1}$. Gaussians function was used to fit the testing FTIR spectrum, the expression was the following ${ }^{10,14}$ :

$$
\mathrm{y}=\mathrm{y}_{0}+\left(\frac{\mathrm{A}}{\mathrm{w} \sqrt{\frac{\mathrm{p}_{\mathrm{i}}}{2}}}\right) \mathrm{e}^{-2\left(\frac{\mathrm{x}-\mathrm{x}_{\mathrm{c}}}{\mathrm{w}}\right)^{2}}
$$

where $\mathrm{y}_{0}$ is the baseline offset, $\mathrm{x}_{\mathrm{c}}$ is the center of the peak, $\mathrm{w}$ equals the width of the peak at half height, $\mathrm{A}$ is the area under the peak.

\section{RESULTS AND DISCUSSION}

XRD patterns and crystallinity study: The XRD patterns (Fig. 1) show that all the samples have similar apatite structure, which is the typical hexagonal structure of hydroxyapatite (matching ICDD 09-0432). Peaks appeared approximately at $30,34,36-40,47$ and $55^{\circ}(2 \theta)$, similar to the characteristic peaks of hydroxyapatite. Considering that sharp and narrow characteristic peaks means good crystallinity, all the samples have a barely crystallized apatite structure. The characteristic peaks of natural bone are weaker than the synthetic samples, which imply natural bone apatite has a relative poorer crystallinity. On the other hand, sample 1 has the most distinct characteristic peaks and higher crystallinity ${ }^{15}$. Among the three synthetic samples, sample 3 has the weakest crystallinity which is closer to natural bone apatite than the other two samples, which may be ascribed to distortion of the apatite unit cell by more carbonate substitution in its structure. The crystallinity is an important factor for apatite-based biomaterials. Generally, well-crystallized structure suggests a relative low bioactivity. In contrast, nanocrystalline or bio-crystal apatite, is typically non-stoichiometric and weak crystalline, exhibit a much higher degree of bioactivity.

The weak peaks at 34.5 and $44.5^{\circ}$ in Fig. $1 \mathrm{~b}$ of sample 2 are attributed to $\mathrm{CaCO}_{3}$, since there were many $\mathrm{Ca}^{2+}$ ions in the solution when $\mathrm{CO}_{3}{ }^{2-}$ groups were introduced during the preparation, then, some $\mathrm{CaCO}_{3}$ precipitates formed. The small peaks of $\mathrm{CaCO}_{3}$ are also present in Sample 1 (Fig. 1a), which may attribute to the carbon dioxide from air.

It can be seen from Fig. 1 that sample 3 is more similar to natural bone apatite in terms of component, structure and crystallinity. 


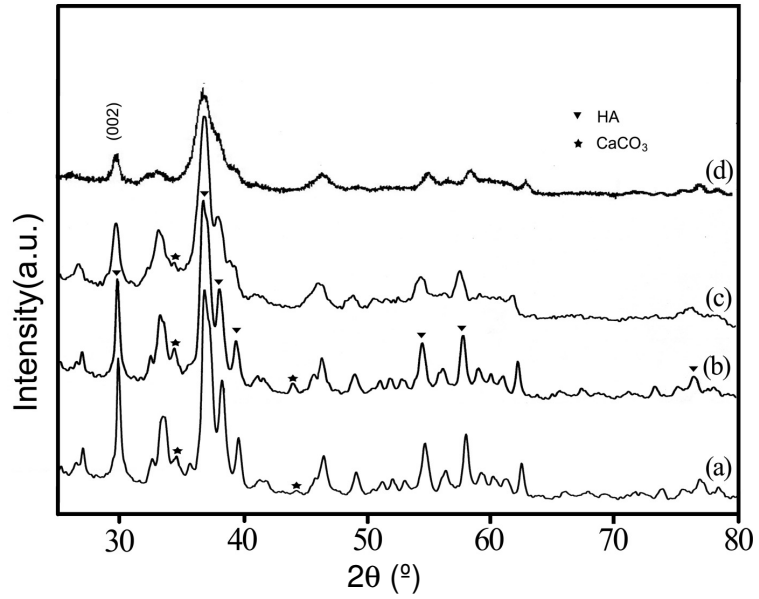

Fig. 1. XRD patterns of different samples with Co radiation: (a) Sample 1; (b) Sample 2; (c) Sample 3; (d) natural bone

Theoretical crystal energy calculation of type-A carbonated hydroxyapatite, type-B carbonated hydroxyapatite and standard hydroxyapatite: The hydroxyapatite structure allows the substitution of their $\mathrm{Ca}^{2+}, \mathrm{PO}_{4}{ }^{3-}$ and $\mathrm{OH}^{-}$ions or groups by other ions or chemical groups, especially by $\mathrm{CO}_{3}{ }^{2-}$ . There are two types of $\mathrm{CO}_{3}{ }^{2-}$ substitution labeled as type-A and type-B, depending on whether they occupy the $\mathrm{OH}^{-}$ (Fig. 2a) or $\mathrm{PO}_{4}{ }^{3-}$ (Fig. 2b) sites in hydroxyapatite structure ${ }^{16}$.

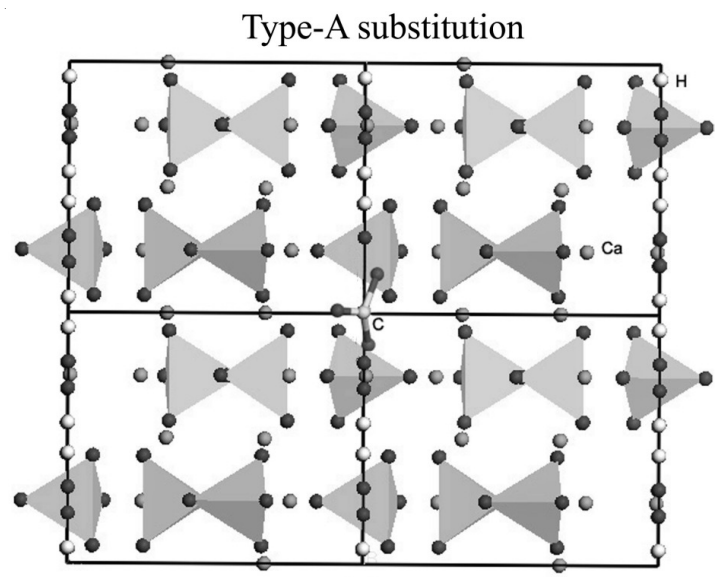

(a)

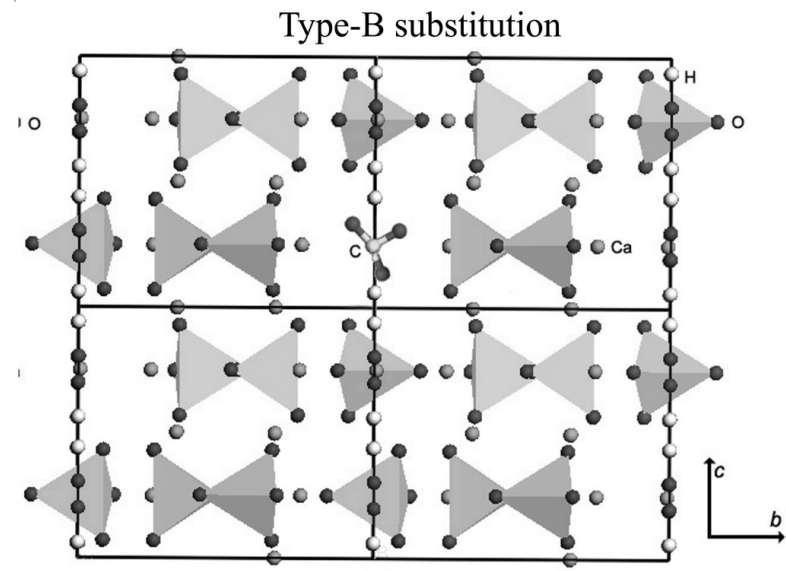

(b)

Fig. 2. Structures of carbonated hydroxyapatite: (a) Type-A carbonate substitution; (b) Type-B carbonate substitution
Materials Studio 4.0 is used to calculate the crystal energy of samples in order to analyze the stability of different samples. The total energy of a crystal can be divided into the energy of valence and the energy of non-bond. The latter includes van der Waals (VdW), electrostatic (Coulomb) and hydrogen bond (H-bond). But in apatite, the energy of non-bond is mainly from van der Waals, so the total energy of apatite could be described in eqn. 7 :

$$
\mathrm{E}_{\text {Total }}=\mathrm{E}_{\text {Valence }}+\mathrm{E}_{\mathrm{VdW}}
$$

The structure models of type-A and type-B carbonated hydroxyapatite were constructed separately. Table-1 shows the crystal energy of standard hydroxyapatite, type-A carbonated hydroxyapatite and type-B carbonated hydroxyapatite, which were calculated from the corresponding structure models. As shown in Table-1, the hydroxyapatite with type-B substitution has similar energy to standard hydroxyapatite. Both of their energies are lower than that of type-A carbonated hydroxyapatite. In general, lower crystal energy of the unit cell indicates better stability, thus hydroxyapatite without substitution has best stability. The crystal energy of type-A carbonated hydroxyapatite is much greater than others, resulting in more instability. Therefore, type-B substitution has more possibility of existence than type-A substitution. However, the substitutions in natural bone and synthetic carbonated hydroxyapatites are not single type-A or type-B substitution. Furthermore, the mixture of them and type-B substitutions are more common than type-A substitution for lower crystal energy.

\begin{tabular}{|c|c|c|c|}
\hline \multicolumn{4}{|c|}{$\begin{array}{c}\text { TABLE-1 } \\
\text { THE CRYSTAL ENERGY OF TYPE-A CARBONATED } \\
\text { HYDROXYAPATITE, TYPE-B CARBONATED } \\
\text { HYDROXYAPATITE AND STANDARD HYDROXYAPATITE }\end{array}$} \\
\hline $\begin{array}{c}\text { Energy } \\
(\mathrm{kcal} / \mathrm{mol})\end{array}$ & Type-A CHA & Type-B CHA & Standard HA \\
\hline Total energy & -971515.074 & -15156.246 & -15138.966 \\
\hline Valence energy & -12825.458 & -13535.924 & -13505.941 \\
\hline Van der Waals & -958689.617 & -1620.323 & -1633.025 \\
\hline
\end{tabular}

Calculation and analysis of lattice parameters: The lattice parameters of different samples are calculated by software Jade 6.5 and showed in Table-2. Compared with sample 1, Sample 2 has a smaller a parameter of $9.42972 \AA$ and bigger c parameter of $6.91502 \AA$. Sample 3 shows the same trend in the changes of a and c parameters, but more remarkable. The changes of parameters result mainly from the carbonate substitution of type-A or/and type-B in their structures. Such substitutions will lead to changes of structural properties, e.g., lattice parameters, crystallinity and morphology. Among these changes, the change in lattice parameter is one of the most conspicuous characteristics of the apatite structure.

For type-A defect, due to the fact that a carbonate group has greater bulk than a hydroxyl group, the incorporation of type-A carbonate defects in the channel cause an increase in the a-dimension, especially as the carbonate is lined up in the c-direction with two of its oxygens above and below the carbon atom.

For type-B defect, both of the two type-B defects have the same trend on the changes in a- and b-parameters, yet differ on degrees. The carbonate group is smaller than a phosphate, 
TABLE-2

LATTICE PARAMETERS OF DIFFERENT SAMPLES

\begin{tabular}{cccccc}
\hline Lattice parameters & Sample 1 & Sample 2 & Sample 3 & Standard HA & Natural bone \\
\hline $\mathrm{a}=\mathrm{b}$ & $9.45041 \AA$ & $9.42972 \AA$ & $9.39741 \AA$ & $9.36-9.64 \AA$ & $9.39110 \AA$ \\
$\mathrm{c}$ & $6.90704 \AA$ & $6.91502 \AA$ & $6.92566 \AA$ & $6.78-6.90 \AA$ & $6.92284 \AA$ \\
$\alpha=\beta$ & $90^{\circ}$ & $90^{\circ}$ & $90^{\circ}$ & $90^{\circ}$ & $90^{\circ}$ \\
$\gamma$ & $120^{\circ}$ & $120^{\circ}$ & $120^{\circ}$ & $120^{\circ}$ & $120^{\circ}$ \\
Crystallite size (SD) & $322 \AA(32)$ & $286 \AA(28)$ & $93 \AA(6)$ & - & $60 \AA(4)$ \\
Lattice stain & $0.0297 \%$ & $0.0426 \%$ & $0.0712 \%$ & - & $0.1920 \%$ \\
\hline
\end{tabular}

thus, when a carbonate is substituted for a phosphate, the contraction in the a- and b-parameters. For the $\mathrm{CO}_{3} / \mathrm{OH}$ defect, the decrease in the c-parameter is much less than the a-direction, due to the extra charge compensating $\mathrm{OH}^{-}$ion incorporated in the lattice. Together the $\mathrm{CO}_{3}{ }^{2-}$ and $\mathrm{OH}^{-}$groups form a rather bulky defect, which distorts the lattice, leading to the unequal modifications of the a- and c-parameters. As for $\mathrm{CO}_{3} / \mathrm{Na}$ defect, because $\mathrm{Na}^{+}$has similar ionic radii to $\mathrm{Ca}^{2+}$, the decrease in lattice parameters for $\mathrm{Na}^{+}$is completely due to the smaller carbonate group occupying a phosphate lattice position. Therefore, $\mathrm{CO}_{3} / \mathrm{Na}$ defect has more decrease in the a- and c-parameters ${ }^{17-19}$.

Compared with sample 1, the change of lattice parameter indicates that $\mathrm{CO}_{3}{ }^{2-}$ substitution exists in sample 2 and sample 3 , including type-A and type-B substitution. Bigger changes in lattice parameters predict more substitution of $\mathrm{CO}_{3}{ }^{2-}$ groups in the structure. Sample 3 shows bigger changes in lattice parameters than sample 2, revealing more carbonate substitution in its structure, as well as a greater distortion of the apatite unit cell.

Calculation of crystallite size and supersaturation degree: Table-3 shows the molecular formulas for different samples, which are calculated from chemical analyses. Compared with standard hydroxyapatite, $\mathrm{CO}_{3}{ }^{2-}$ groups exist in all samples. The formula can be expressed by $\mathrm{CaK}\left(\mathrm{PO}_{4}\right) \mathrm{L}\left(\mathrm{CO}_{3}\right) \mathrm{M}(\mathrm{OH}) \mathrm{N}$, in which the value of $\mathrm{K}, \mathrm{L}, \mathrm{M}$ and $\mathrm{N}$ changes with the carbonate content. The molecular formula of sample 1 is closer to standard hydroxyapatite $\left[\mathrm{Ca}_{10}\left(\mathrm{PO}_{4}\right)_{6}(\mathrm{OH})_{2}\right]$. Reversely, sample 3 has more carbonate content $(3.43 \mathrm{wt} \%)$ than sample 1 (2.28 wt \%) and sample $2(2.70 \mathrm{wt} \%)$, indicating more carbonate substitution present in its structure ${ }^{20}$. But, all the samples have lower carbonate content than natural bone (4-8 wt \%).

In Table-3, the crystallite sizes of different samples are calculated by the Scherrer formula of eqn. 1 . The results show that the crystallite size decreases with the increase of $\mathrm{CO}_{3}{ }^{2-}$ content in the molecular formula. The crystallite size of Sample 1 is $322 \AA$, but the crystallite size of Sample 3 is only $93 \AA$, which is closer to the size of natural bone apatite.

The classical theory of nucleation and growth is taken to analyze the effect of $\mathrm{CO}_{3}{ }^{2-}$ on the samples. Supersaturation $(\mathrm{S})$ is defined as:

$$
\mathrm{S}=\frac{\mathrm{IAP}}{\mathrm{K}_{\mathrm{sp}}}
$$

where IAP is the ionic activity product and $\mathrm{K}_{\mathrm{sp}}$ is the sample solubility constant at $37^{\circ} \mathrm{C}\left(\mathrm{K}_{\mathrm{sp}}=10^{-58.63} \mathrm{~mol}^{2} / \mathrm{L}^{2}\right)$.

IAP is calculated using the equation:

$$
\begin{aligned}
\log \mathrm{IAP}=\mathrm{K} & \log \alpha\left(\mathrm{Ca}^{2+}\right)+\mathrm{L} \log \alpha\left(\mathrm{PO}_{4}{ }^{3-}\right) \\
& +\mathrm{M} \log \alpha\left(\mathrm{CO}_{3}{ }^{2-}\right)+\mathrm{N} \log \alpha\left(\mathrm{OH}^{-}\right)
\end{aligned}
$$

where $\alpha$ ( ) denotes activity (mol/L); K, L, M, N correspond to the expression $\mathrm{Ca}_{\mathrm{K}}\left(\mathrm{PO}_{4}\right)_{\mathrm{L}}\left(\mathrm{CO}_{3}\right)_{\mathrm{M}}(\mathrm{OH})_{\mathrm{N}}$.

The calculated supersaturation degrees are shown in Table3. The supersaturation degree increases with the carbonate content. According to the classical theory of nucleation ${ }^{21-23}$, an increase of supersaturation produces a decrease of the nucleation activation energy and consequently an increase of the nucleation rate may occur. Accordingly, sample 3 has a higher supersaturation degree, leading to a smaller crystallite size.

FTIR analysis and the calculated ratio of type-B to type-A substitution: The FTIR spectra in Fig. 3 show the characteristic absorption peaks of different samples. All samples have similar bands at 1090-1040, 963-960 and 603$570 \mathrm{~cm}^{-1}$. As a major peak of hydroxyapatite, the broad band at about $1090-1040 \mathrm{~cm}^{-1}$ belongs to $v_{3}$ non-symmetrical stretch of $\mathrm{PO}_{4}{ }^{3-}$. The weak band at $963-960 \mathrm{~cm}^{-1}$ attributes to $v_{1}$ symmetrical stretch of $\mathrm{PO}_{4}{ }^{3-}$. The band between 565 and 603 $\mathrm{cm}^{-1}$ belongs to $\mathrm{V}_{4}$ vibration mode of $\mathrm{PO}_{4}{ }^{3-}$ group, which occupies two sites in the crystal lattice (at 601 and $567 \mathrm{~cm}^{-1}$ ). Two distinguishable splitting of $v_{4}$ vibrations indicates the low site symmetry of molecules, as two peaks confirm the presence of more than one distinction site for the phosphate group in hydroxyapatite lattice ${ }^{24,25}$.

In the region of $1480-1420 \mathrm{~cm}^{-1}$, all samples display a similar band that belongs to $\mathrm{V}_{3}$ non-symmetrical stretch of $\mathrm{CO}_{3}{ }^{2-}$. Elliot ${ }^{26}$ considered the $\mathrm{CO}_{3}{ }^{2-}$ spectral positions of simple type-A substitution located at $884 \mathrm{~cm}^{-1}\left(V_{2}\right)$ and $1534 \mathrm{~cm}^{-1}$ (divided into $v_{3 a}-1534 \mathrm{~cm}^{-1}$ and $v_{3 b}-1465 \mathrm{~cm}^{-1}$ ), while the $\mathrm{CO}_{3}{ }^{2-}$ spectral positions of simple type-B substitution were at $864 \mathrm{~cm}^{-1}\left(\mathrm{~V}_{2}\right)$ and $1455 \mathrm{~cm}^{-1}$ (divided into $\mathrm{v}_{3 \mathrm{a}}-1455 \mathrm{~cm}^{-1}$ and $\mathrm{v}_{3 \mathrm{~b}}-1430 \mathrm{~cm}^{-1}$ ). Therefore, the bands near $1476 \mathrm{~cm}^{-1}$ were complex bands of $v_{3 a}$ of type-A substitution and $v_{3 b}$ of type-B substitution. The small band at the $v_{3}$ region in the spectrum of sample 1 (Fig. $3 a$ ) is due to the presence of carbonate ions that probably entered the structure from atmospheric $\mathrm{CO}_{2}$ during the synthesis.

A sharp band is clearly distinguished at about $867 \mathrm{~cm}^{-1}$ for all samples except for sample 1 . The band is ascribed to

TABLE-3

MOLECULAR FORMULA, CARBONATE CONTENT AND SUPERSATURATION DEGREE FOR DIFFERENT SAMPLES

\begin{tabular}{cccc}
\hline Spec. & m.f. & Carbonate content $($ wt \%) & Super saturation degree \\
\hline Sample 1 & $\mathrm{Ca}_{9.874}\left(\mathrm{PO}_{4}\right)_{5.901}\left(\mathrm{CO}_{3}\right)_{0.385}(\mathrm{OH})_{1.952}$ & 2.28 & 29 \\
Sample 2 & $\mathrm{Ca}_{9.596}\left(\mathrm{PO}_{4}\right)_{5.624}\left(\mathrm{CO}_{3}\right)_{0.437}(\mathrm{OH})_{1.768}$ & 2.70 & 36 \\
Sample 3 & $\mathrm{Ca}_{9.347}\left(\mathrm{PO}_{4}\right)_{4.920}\left(\mathrm{CO}_{3}\right)_{0.512}(\mathrm{OH})_{1.421}$ & 3.43 & 72 \\
\hline
\end{tabular}




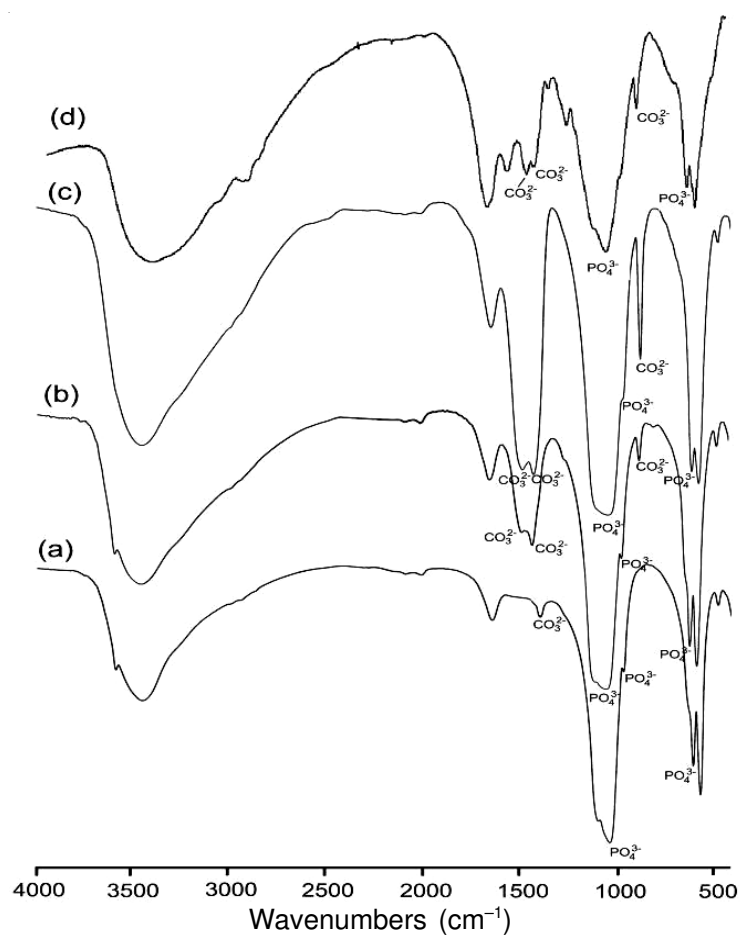

Fig. 3. FTIR spectra of different samples: (a) Sample 1; (b) Sample 2; (c) Sample 3; (d) natural bone

the complex of two vibrations: $v_{2}$ of type-A substitution and $v_{2}$ of type-B substitution, which could be divided into the band of type-A substitution and the band of type-B substitution by Gaussians function. The characteristic band of $\mathrm{CO}_{3}{ }^{2-}$ substitution not present at $c a .870 \mathrm{~cm}^{-1}$ in sample 1 is because the band of $\mathrm{CO}_{3}{ }^{2-}$ substitution is too weak to see, as mentioned above. Fig. 4 shows the fitting spectrum of the band at 867 $\mathrm{cm}^{-1}$ for Sample 2 while Fig. 5 is the fitting result of Sample 3 at $872 \mathrm{~cm}^{-1}$ by Gaussians function (eqn. 3). The strong 864 $\mathrm{cm}^{-1}$ band is assigned to the type-B carbonate substitution and the lower intensity band at $884 \mathrm{~cm}^{-1}$ is assigned to the type-A carbonate substitution. Both sample 2 and sample 3 have more type-B substitution than type-A substitution in their structure for the aforementioned reason in crystal energy calculation. From the fitting spectrum, the probable ratio of type-B substitution to type-A substitution can be estimated by comparing the intensity of type-B substitution with the intensity of type-A substitution. All the corresponding ratios are listed in Table-4. Compared with other samples, sample 3 has the most similar ratio with natural bone apatite.

\begin{tabular}{cc} 
TABLE-4 \\
RATIO OF TYPE-B SUBSTITUTION TO TYPE-A \\
SUBSTITUTION FOR DIFFERENT SAMPLES \\
\hline Sample & Type-B/Type-A ratio \\
\hline Sample 1 & n.a. \\
Sample 2 & 3.4898 \\
Sample 3 & 3.6176 \\
Natural Bone & 4.5282 \\
\hline
\end{tabular}

The sharp band at $3570 \mathrm{~cm}^{-1}$ in the spectra of sample 1 and Sample 2 is assigned to the $\mathrm{OH}^{-}$stretching mode. Absence of this band from the spectrum of sample 3 implies that there are also many type-A carbonate substitution present in its

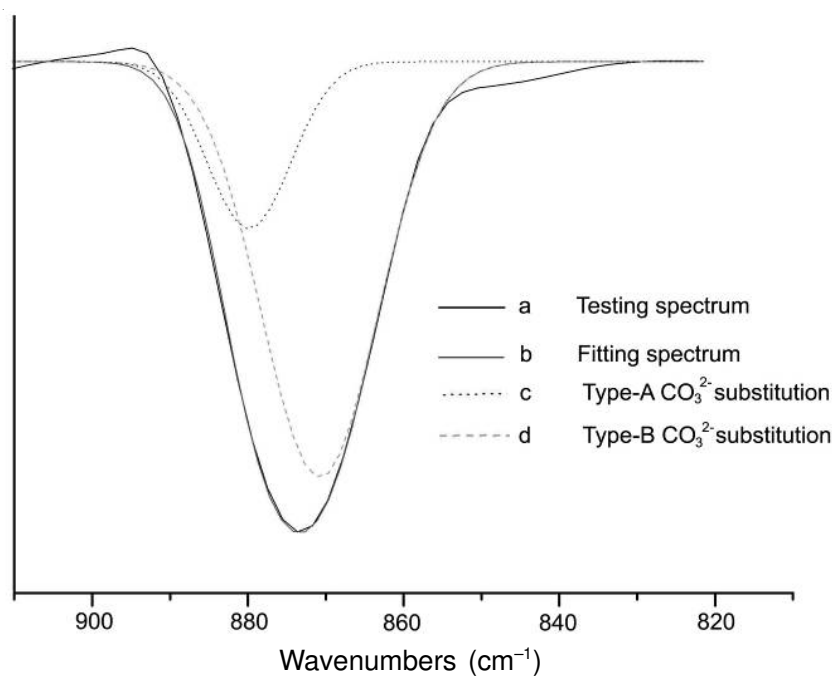

Fig. 4. Fitting spectrum for sample 2

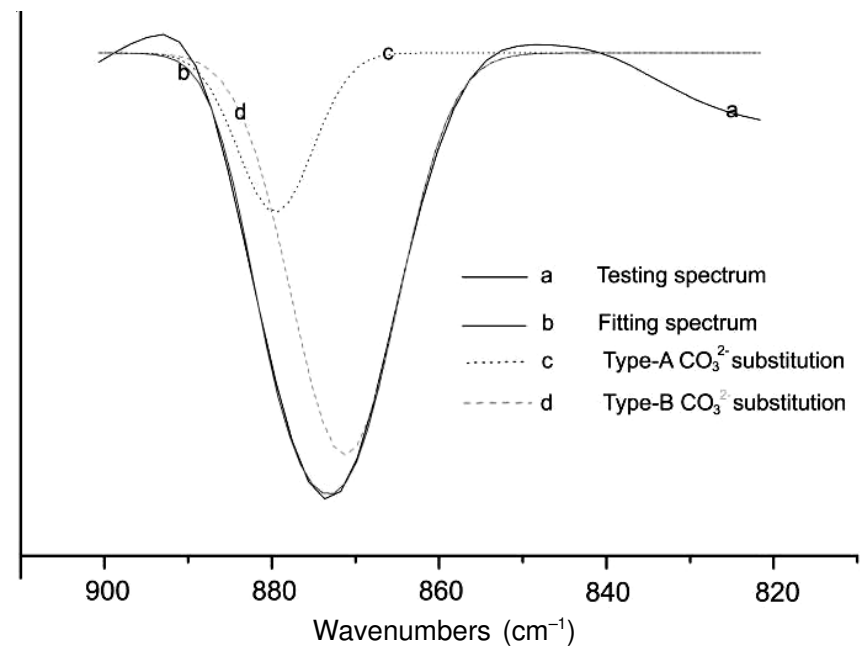

Fig. 5. Fitting spectrum for sample 3

structure and the carbonate groups occupy the $\mathrm{OH}^{-}$sites. Due to the production of $\mathrm{CaCO}_{3}$ precipitates, less $\mathrm{CO}_{3}{ }^{2-}$ ions take part in the carbonate substitution, so a weak band appears at $3570 \mathrm{~cm}^{-1}$ in the spectrum of Sample 2. Whether $\mathrm{OH}^{-}$exists in natural bone is uncertain at present. In this study, the band of $\mathrm{OH}^{-}$at $3570 \mathrm{~cm}^{-1}$ is also not found in the spectrum of natural bone apatite. From this point as well as the observed similarity of XRD patterns and FTIR spectra, Sample 3 has more similarity with natural bone apatite.

\section{Conclusion}

In this study, hydroxyapatite and carbonated hydroxyapatite samples with different reaction sequence are prepared. Software Jade 6.5, Materials Studio 4.0 and Origin 7.0, are used to analyze the crystal energy, as well as the structure change and the crystallite size, of all samples including natural bone apatite. The XRD patterns show that when $\mathrm{CO}_{3}{ }^{2-}$ ions are added into the solution after the reaction, the carbonated hydroxyapatite sample has the lowest crystallinity, more comparable to natural bone apatite. The crystal energy calculated by Materials Studio 4.0 indicates that the carbonated hydroxyapatite with type-B substitution has a relative lower crystal energy and a better stability. The changes in lattice parameters 
obtained from the refinement of Jade 6.5 also prove that the $\mathrm{CO}_{3}{ }^{2-}$ substitution results in the distortion of the crystal structure. The supersaturation degree suggests that the carbonated hydroxyapatite has smaller crystallite size when more $\mathrm{CO}_{3}{ }^{2-}$ ions exist in the structure. The fitting FTIR spectra show that there is more type-B than type-A substitution in all samples. From the computation results of Gaussians function, the ratio of type-B substitution to type-A substitution increases with the carbonate content.

\section{ACKNOWLEDGEMENTS}

This work was financially supported by Natural Science Foundation of China (51202302) and Natural Science Foundation Project of CQ CSTC (CSTC2012JJA50020).

\section{REFERENCES}

1. A. Antonakos and E. Liarokapis, Biomaterials, 28, 3043 (2007).

2. R. Murugan, S. Ramakrishna and K.P. Rao, Mater. Lett., 60, 2844 (2006).

3. Lan Wu, Dissertation, Sichuan University, Sichuan, China (2006).

4. M. Wakamura, K. Kandori and T. Ishikawa, Colloid. Surf. A,164, 297 (2000).
5. M.H. Fathi, A. Hanifi and V. Mortazavi, J. Mater. Proc. Technol., 202, 536 (2008).

6. R. Murugan and S. Ramakrishna, Acta Biomed., 2, 201 (2006)

7. F. Miyaji, Y. Kono and Y. Suyama, Mater. Res. Bull., 40, 209 (2005).

8. M. Iafisco and J.G. Morales, Adv. Eng. Mater., 12, B218 (2010).

9. I.R. Gibson and W. Bonfield, J. Biomed. Mater. Res., 59, 697 (2009).

10. S. Peroos, Z.M. Du and N.H. de Leeuw, Biomaterials, 27, 2150 (2006).

11. K. Kawabata and T. Yamamoto, J. Ceram. Soc. (Japan), 118, 548 (2010).

12. K. Matsunaga and H. Murata, J. Phys. Chem. B, 113, 3584 (2009).

13. T. Ikoma and A. Yamazaki, J. Solid State Chem., 144, 272 (1999).

14. L. Lv, L.H. Guo and Y.X. Zhang, J. Chin. Ceram. Soc., 32, 177 (2004).

15. D.D. Heslop, Y. Bi and A.A. Baig, J. Colloids Interf. Sci., 289, 14 (2005).

16. M.E. Fleet and Xi Liu, Biomaterials, 28, 916 (2007).

17. M.E. Fleet and X.Y. Liu, Biomaterials, 26, 7548 (2008).

18. M.E. Fleet and X.Y. Liu, J. Solid State Chem., 177, 3174 (2005).

19. R.M. Wilson, S.E.P. Dowker and J.C. Elliott, Biomaterials, 27, 4682 (2006).

20. N.Y. Mostafa and P.W. Brown, J. Phys. Chem. Solid., 68, 431 (2007).

21. R. Astala and M.J. Stott, Chem. Mater., 17, 4125 (2005).

22. H.R. Low, C. Ritter and T.J. White, Dalton Trans., 6488 (2010).

23. S. Cai, Y.W. Wang and H. Lv, Ceram Int., 31, 135 (2005).

24. L. Müller, E. Conforto and D. Caillard, Biomed. Eng., 24, 462 (2007).

25. Q.J. He, Z.L. Huang and X.K. Cheng, Mater. Lett., 62, 539 (2008)

26. J.C. Elliot, Calc. Tiss. Res., 3, 293 (1969). 